\title{
Epistemic modals, deduction, and factivity: New insights from the epistemic future*
}

\author{
Teodora Mihoc \\ Harvard University
}

\author{
Diti Bhadra \\ University of Minnesota
}

\author{
Anamaria Fălăuş \\ CNRS / Nantes University
}

\begin{abstract}
The epistemic future (e.g., the epistemic uses of English will) is often analyzed on a par with epistemic must. We provide novel empirical evidence from English and Romanian in deduction and factive contexts to argue that this identical treatment is not warranted. We propose a unified solution based on novel ways to (i) look at weakness in must and will and (ii) encode the factive presupposition when the complement of the factive is a modalized proposition (an interaction that, to our knowledge, has not been analyzed formally before). The account connects to existing debates on strength in necessity modals, on epistemic future and future tense, and on the embedding of epistemic (and other flavor) modals under attitudes.
\end{abstract}

Keywords: epistemic modals, epistemic future, deduction, factive cognitive attitudes

\section{Introduction}

Consider the English sentence in (1) below. In this sentence the auxiliary will can have two interpretations. On one interpretation, will is understood as simply saying that Anna's being home is located after the time of utterance, and does not convey any speaker uncertainty about the truth of the prejacent - the speaker believes it to be true. This interpretation can be paraphrased as in (1a) and is essentially understood as an expression of future temporality (FUT). On the other interpretation, will is understood as saying that Anna's being home is located at or after the time of utterance and also conveys some speaker uncertainty about the truth of the prejacent - the speaker believes it to be merely likely to be true, given what s/he knows. This interpretation can be paraphrased as in (1b) and is essentially understood as an expression of epistemic modality (EPI).

* For helpful comments and suggestions, we thank Gennaro Chierchia, the audience at SALT 29, and our informants for English (Shannon Bryant, Zuzanna Fuchs, Josh Martin, Tamisha Tan, Nick Winter, Chantale Yunt). 
(1) Anna will be home.

a. Anna is guaranteed to be home at some point in the future.

FUT $\checkmark$

b. Anna is likely to be home now / at some point in the future, given what the speaker knows.

EPIS

The fact that a future temporal and an epistemic modal interpretation are obtained through the same morphology is not an accident of English - it is indeed crosslinguistically very common (see, e.g., Winans 2016 or Giannakidou \& Mari 2018 for languages and references). Below we illustrate this with Romanian $v a$, which, like English will, can convey both a future tense and an epistemic modal meaning.

Anna va fi acasă.

Anna VA be home

'Anna will be home.'

Romanian; FUT $\checkmark$, EPI $\checkmark$

For both English will and Romanian va the future temporal interpretation has come to be the more dominant one, and the epistemic interpretation increasingly less accessible (with variation across speakers or dialects). While in English this seems to be leading to the epistemic future being phased out, in Romanian it has led to the epistemic future acquiring a morphology of its own: $o$ in (3) is morphologically derived from $v a$ but can only convey the epistemic modal meaning (cf. Mihoc 2012).

(3) Anna o fi acasă.

Anna o be home

'Anna will be home.'

Romanian; FUTX, EPI

The future temporal interpretation of will and $v a$ is often referred to simply as the 'future tense' and the epistemic modal interpretation of will, $v a$, and $o$ as the 'epistemic future'. In this paper we focus on this latter epistemic future interpretation only, aiming to explain how it compares to more canonical epistemic modals. Since intuitions about this interpretation are less clear for the ambiguous will/va than for the unambiguous $o$, in what follows we will throughout draw on all three forms.

The existing literature typically paraphrases the epistemic future (at least in plain declaratives) as must (e.g., Condoravdi 2003 for English; Mihoc 2012; Fălăuș 2014 for Romanian; Fălăuș \& Laca 2014 for Spanish; Ippolito \& Farkas 2018 for Romanian and Italian; Giannakidou \& Mari 2016, 2018 for Greek and Italian). These paraphrases have been used to argue for a fundamental similarity between the two categories and have been fruitful in developing formal accounts of the epistemic future (or of the future more generally) as an epistemic modal. At the same time, it is also clear that this similarity doesn't always hold - there are contexts where epistemic must is fine and the epistemic future is not (e.g., Winans 2016; Fălăus 
Epistemic modals, deduction, and factivity

2014; Ippolito \& Farkas 2018; etc.), and also contexts where the epistemic future is fine and epistemic must is not (e.g., Mihoc 2012, 2014; Fălăuș 2014; Ippolito \& Farkas 2018, a.o.). In what follows we focus on two contrasts of the former type (both noticed in Fălăuș 2014, without a formal treatment).

The first contrast between epistemic must and the epistemic future - to which we will refer as THE CERTAINTY PUZZLE - has to do with acceptability in unembedded environments, depending on speaker (un)certainty / (non-)deduction (cf. Goodhue 2017 for a description of these contexts as (non-)deduction contexts).

In a context as below where the speaker is not entirely sure that the conclusion is true / the conclusion doesn't follow from the facts - if it is $7 \mathrm{pm}$ and at $7 \mathrm{pm}$ Anna is typically home, that only makes it likely that she is home now, but doesn't guarantee it - both epistemic must and the epistemic future are felicitous.

(4) Unembedded, uncertainty context

Jo is looking for Anna. Jo checks the time: It's 7 pm. Jo knows that at 7 pm Anna is typically home. Jo concludes:

a. Anna must be home now.

b. Anna will be home now.

c. Ana va fi acasă la ora asta.

Anna VA be home at hour this

d. Ana o fi acasă la ora asta.

Anna o be home at hour this

However, in a context as below where the speaker is entirely sure that the conclusion is true / the conclusion does follow from the facts - if it is $7 \mathrm{pm}$ and at 7 pm Anna is always home, that guarantees that she is home now - epistemic must continues to be felicitous but the epistemic future is not. (Of course, always rarely really means always in real life, but the point is that Jo takes it as such.)

Unembedded, certainty context

Jo is looking for Anna. Jo checks the time: It's 7 pm. Jo knows that at 7 pm Anna is always home. Jo concludes:

a. Anna must be home now.

b. \# Anna will be home now.

c. \# Ana va fi acasă la ora asta.

Anna VA be home at hour this

d. \# Ana o fi acasă la ora asta.

Anna o be home at hour this

The same can be seen, perhaps even more clearly, from a context as below: 
(6) If $\mathrm{x}$ is divisible by 2 , then $\mathrm{x}$ is even. 2 is divisible by 2 .

So, 2 \must / \# will / \# va / \# o be even.

Similar contrasts are given in (7) (cf. von Fintel \& Gillies 2010 for must, also used in Fălăus 2014 for Romanian $o$ ) and (8) ( cf. Mandelkern 2019: 248 on must, also used in Ippolito \& Farkas 2018 for the epistemic future):

(7) Chris has lost her ball, but she knows with full certainty that it is either in Box A or B or C. She says: The ball is in A or in B or in C. It is not in A ... It is not in $\mathrm{B}$...

So, it $\checkmark$ must / \# will / \# va / \# o be in C.

(8) If the set of validities were decidable, then the halting problem would be decidable. The halting problem is not decidable.

So, the set of validities $\checkmark$ must / \# will / \# va / \# o be undecidable.

The second contrast between epistemic must and the epistemic future - to which we will refer as THE FACTIVITY PUZZLE - has to do with embedding in the complement of a cognitive attitude predicate, depending on (non-)factivity.

When embedded under a non-factive cognitive attitude predicate such as think, guess, or suspect, both epistemic must and the epistemic future are fine.

(9) Embedded, complement of non-factive cognitive attitude

a. I think that Anna must be home now.

b. I think that Anna will be home now. ${ }^{1}$

c. Cred că Ana va fi acasă la ora asta. think.1SG that Anna VA be home at hour this

d. Cred că Ana o fi acasă la ora asta. think.1SG that Anna o be home at hour this

However, when embedded under a factive cognitive attitude predicate such as find out, epistemic must is fine whereas the epistemic future is not.

(10) Embedded, complement of factive cognitive attitude

a. I just found out that Anna must be home now.

b. \# I just found out that Anna will be home now.

c. \# Tocmai am aflat că Ana va fi acasă la ora asta. just found.out.1SG that Anna VA be home at hour this

1 Some native speakers find this slightly degraded, but then agree that it improves if "Anna" is replaced with a pronoun, if that is removed, and if contraction is used: I think she'll be home now. 
Epistemic modals, deduction, and factivity

$$
\begin{aligned}
& \text { d. \# Tocmai am aflat că Ana o fi acasă la ora asta. } \\
& \text { just found.out.1SG that Anna o be home at hour this }
\end{aligned}
$$

The same happens with other factive cognitive attitude predicates, e.g., realize, discover, know, which consistently rule out the epistemic future in their complement.

In order to account for these puzzles, we need to understand (i) why epistemic must is compatible with both an uncertainty/non-deduction and a certainty/deduction context whereas the epistemic future only with the former; and (ii) why epistemic must is compatible with both a non-factive and a factive cognitive attitude, whereas the epistemic future only with the former. The existing literature provides many insights, yet a full explanation for all these facts is still missing. Our goal in what follows is to argue that the two contrasts are related and to provide a unitary account, which captures the distribution of must and the epistemic future in both unembedded and embedded contexts. We offer a unified account, arguing that epistemic must and the epistemic future are both epistemic necessity modals, but the former allows an empty ordering source while the latter does not. We show that this straightforwardly captures the certainty puzzle and, with existing assumptions about epistemic modal embedding under attitude predicates and a novel view of the factive presupposition of such predicates generalized for modalized complements, the factivity puzzle also.

\section{Proposal: the certainty puzzle}

The certainty puzzle concerns the fact that both epistemic must and the epistemic future can be used in uncertainty/non-deduction contexts, but only epistemic must can also be used in certainty/deduction contexts. Our proposed solution is as below.

\subsection{Capturing the similarity in uncertainty/non-deduction contexts}

On a simple view of modality, modals are interpreted relative to a conversational background. The conversational background is a function $f$ that assigns to a world $w$ the set of propositions encoding what is known (epistemic) / believed (doxastic) / allowed (deontic) / etc. at $w$. The global intersection of these propositions, $\cap f(w)$, provides the set of worlds compatible with what is known/believed/allowed/etc. at $w$. This set of worlds is what the modal quantifies over. Specifically, given an evaluation world $w$, a possibility/necessity modal takes as an argument a conversational background $f$ and a proposition $p$ and yields true iff some/all the worlds in $\bigcap f(w)$ are worlds where $p$ is true. In particular, an epistemic necessity modal takes as an argument a conversational background $f$ that assigns to $w$ a set of propositions encoding what is known at $w$, and a proposition $p$, and yields true iff all the worlds in $\bigcap f(w)$ are worlds where $p$ is true. 


$$
\llbracket \text { must } \rrbracket^{w}=\lambda f_{\langle s,\langle\langle s, t\rangle t\rangle\rangle} \cdot \lambda p_{\langle s, t\rangle} \cdot \forall w^{\prime} \in \bigcap f(w)\left[p\left(w^{\prime}\right)\right]
$$

Note that, if $f(w)$ are propositions that are true at $w$, that means that each of them contains $w$, so their global intersection $\bigcap f(w)$ also must. As a result, the truth conditions, which guarantee that all the worlds in $\bigcap f(w)$ are worlds where $p$ is true, guarantee that $w$ itself is a world where $p$ is true. Accordingly, must $p$ entails $p$.

But, if must $p$ entails $p$, we expect it to be stronger, or at least as strong, as $p$. However, as Karttunen (1972) pointed out, this seems wrong - intuitions for an utterance of $p$ versus must $p$, cf. below, suggest that must $p$ is, if anything, weaker.

a. Anna is home.

b. Anna must be home.

$\leftarrow$ perceived to be weaker!

Karttunen suggested that this is because, contrary to what is predicted on a simple view of modality, the truth of must $p$ "in some way logically follows from [...] facts the speaker knows and some reasonable assumptions that he is willing to entertain" (our emphasis; Karttunen 1972: 12, cited in Goodhue 2017: 3).

We believe Karttunen's characterization captures our intuition about the uncertainty context example as well. In this example, repeated below, the truth of must $p$ logically follows from the fact that it is $7 \mathrm{pm}$ and the assumption (from a typical fact) that if it is 7 pm then Anna is home.

Jo is looking for Anna. Jo checks the time: It's $7 \mathrm{pm}$. Jo knows that at $7 \mathrm{pm}$ Anna is typically home. Jo concludes:

Anna $\sqrt{ }$ must $/ \sqrt{ }$ will $/ \sqrt{ }$ va $/ \sqrt{ }$ o be home now.

To capture facts like the above (and others), Kratzer (1981, 1991, 2012) proposed an updated semantics of modals. On her view, epistemic modals (and other kinds of modals) are interpreted relative to not one but two conversational backgrounds. One is, as before, a modal base $f$ which assigns to a world $w$ propositions that are (taken to be) true at $w$ (epistemic modal base). As before, the global intersection of these propositions, $\cap f(w)$, provides a set of worlds that are compatible with all the propositions that are (taken to be) true at $w$ and which, for the reasons outlined earlier, is a set that always contains $w$. However, this time quantification isn't said to happen over this whole set, but rather over a subset thereof, a set of worlds from $\bigcap f(w)$ judged best according to an additional conversational background $g$, known as the ordering source, which assigns to a world $w$ propositions that are believed to be true at $w /$ stereotypically true at $w /$ reasonable assumptions at $w$. As before, because of the epistemic nature of $f, w$ is guaranteed to be in $\bigcap f(w)$. However, it is not guaranteed to be in the best subset of $\bigcap f(w)$. Thus, on these updated truth conditions, must $p$ evaluated at $w$ only guarantees that $p$ is true in all the best worlds 
Epistemic modals, deduction, and factivity

accessible from $w$, it does not guarantee that it is true at $w$ itself. As a consequence, must $p$ no longer entails $p$.

We believe Kratzer's approach captures the behavior of epistemic must and extends to the epistemic future. To be concrete, given a world of evaluation $w$, epistemic must / the epistemic future in contexts like (13) have the following semantics:

First, they take as an argument a conversational background $f$ which assigns to $w$ propositions true at $w, f(w) ; \bigcap f(w)$ forms the epistemic modal base.

$$
f_{\langle s,\langle\langle s, t\rangle t\rangle\rangle}(w)=\{p: p \text { is (taken to be) true at } w\}
$$

Thus,

$$
\bigcap f(w)=\{w: w \text { is in every } p \text { in } f(w)\}
$$

In our context, this would be the fact that it is $7 \mathrm{pm}$, a fact that strictly speaking, is compatible both with Anna being home and with Anna not being home.

Second, they take as an argument a conversational background $g$ which assigns to $w$ propositions that are stereotypically true / reasonable assumptions at $w$.

$$
g(w)=\{p: p \text { is a belief / stereotypical fact / reasonable assumption in } w\}
$$

In our context, this would be the stereotypical fact that, if it is $7 \mathrm{pm}$, Anna is home.

This doxastic/stereotypical ordering source ranks the worlds in $\bigcap f(w)$ (which are worlds compatible with all the propositions (taken to be) true at $w$ ) according to how well they measure up to the standard set by the propositions in $g(w)$ (propositions encoding what is assumed to be true at $w$ ) as shown below - a world $v$ in $\bigcap f(w)$ is better than another such world $v^{\prime}$ if the set of propositions from $g(w)$ true in $v$ is a superset of the set of propositions from $g(w)$ true in $v^{\prime}$.

$$
\forall v, v^{\prime} \in \bigcap f(w): v \leq_{g(w)} v^{\prime} \text { iff }\{p: p \in g(w) \wedge v \in p\} \supseteq\left\{p: p \in g(w) \wedge v^{\prime} \in p\right\}
$$

In our context, if the worlds in $\bigcap f(w)$ - worlds where it is $7 \mathrm{pm}$ - include both worlds where Anna is home and where Anna is not home, the effect of the ordering source is that the first kind of worlds will rank higher.

Once the worlds in $\bigcap f(w)$ are thus ordered by $g(w)$, (cf. Portner 2009) an additional function, Best, picks out the worlds that are ranked the highest, as below.

$$
\operatorname{Best}(\bigcap f(w), g(w))=\left\{v \in \bigcap f(w): \neg \exists v^{\prime} \in \bigcap f(w): v^{\prime}<_{g(w)} v\right\}
$$

In our context, Best would pick out from $f(w)$ - worlds compatible with the fact that it is $7 \mathrm{pm}$ - only those worlds that were ranked highest by $\leq_{g(w)}$ - that is, worlds where Anna is home.

Third, and last, epistemic must / the epistemic future take as an argument their prejacent $p$. They yield true iff all the worlds picked out by Best $(\cap f(w), g(w))$ are worlds where $p$ is true. 
Mihoc, Bhadra, and Fălăuş

$$
\begin{aligned}
& \llbracket m u s t /[\text { future }] \text {-EPI } \rrbracket^{w} \\
& =\lambda f_{\langle s,\langle\langle s, t\rangle t\rangle\rangle} \cdot \lambda g_{\langle s,\langle\langle s, t\rangle t\rangle\rangle} \cdot \lambda p_{\langle s, t\rangle} \cdot \forall w^{\prime} \in \operatorname{Best}(\bigcap f(w), g(w))\left[p\left(w^{\prime}\right)\right]
\end{aligned}
$$

In our context, this amounts to saying that all the worlds in which it is $7 p m$ is true and in which if it is $7 \mathrm{pm}$, then Anna is home is true are worlds where Anna is home is true. As mentioned earlier, for an epistemic necessity modal, $w$ is guaranteed to be in $\bigcap f(w)$ - worlds where it is $7 \mathrm{pm}$. However, $w$ is not guaranteed to be in the Best subset of $\bigcap f(w)$ - worlds where it is $7 \mathrm{pm}$ and Anna is home. Thus, the truth conditions above do not guarantee that $p$ is true at $w$ itself, which captures the use of epistemic must and the epistemic future in the uncertainty context.

\subsection{Capturing the contrast in certainty/deduction contexts}

Kratzer $(1981,1991)$ 's ordering source was by design meant to weaken the modal base - to make must $p$ not entail $p$ - and thus give rise to uncertainty along the lines we described. But von Fintel \& Gillies (2010) showed with examples like the ones we saw in (5) that must is in fact perfectly compatible with a context of certainty. They argued, against the Karttunen (1972)/Kratzer (1981) view of must, that the difference between must $p$ and $p$ is not one of (lack of) strength (in)ability to entail $p$ - but rather one of (in)directness - to utter must $p$ at $w, p$ cannot already be one of the facts the speaker has direct access to. ${ }^{2}$ This raises the question of how this approach handles our uncertainty contexts, which are explicitly such that they do not entail $p$, yet an utterance of must $p$ is perfectly fine. This case is unexpected on the must $p$-entails- $p$ view of must, yet it is perfectly expected on the Karttunen (1972)/Kratzer (1981) must $p$-does-not-entail- $p$ view of must that we adopted. Is there, then, any way to capture the certainty context while maintaining the explanation for the uncertainty context that we adopted above?

As it turns out, Kratzer's approach has the potential not only for weakness but also for strength. In particular, while she argues that "quite generally, the interpretations of modals depend on both a modal base and an ordering source", she also allows that "either parameter can be filled by the empty conversational background" (Kratzer 2012: 49). We believe this provides the solution to our unembedded, certainty context case. In this context the facts entail $p$. Technically, all the worlds in $\bigcap f(w)$ are worlds in which $p$ is true. As such, no extra assumptions are needed to decide whether $p$. More concretely, since the whole purpose of $g(w)$ is to narrow $\cap f(w)$ down to the $p$-worlds, if all the worlds in $\bigcap f(w)$ are already $p$-worlds, $g(w)$ serves no purpose. We propose that this is a case where the ordering

2 See also Goodhue (2017) for a recent discussion of weakness (cf. Karttunen 1972; Kratzer 1981, 1991, 2012; Giannakidou \& Mari 2018, a.o.) vs. indirectness (cf. von Fintel \& Gillies 2010 a.o.), and new arguments for the former. 
Epistemic modals, deduction, and factivity

source is actually empty. ${ }^{3}$ If epistemic must allows an empty ordering source but the epistemic future is lexically such that it disallows it $-{ }^{*} g(w)=\varnothing-$ then their distribution in unemebedded contexts depending on certainty follows. ${ }^{4}$

\subsection{Predictions and extensions}

\subsubsection{Prediction: must $p$ vs. $p$}

We know that must $p$ is fine in both explicit uncertainty and explicit certainty contexts, and we captured that by saying that it can be deduced from either facts+assumptions or just facts. What about plain $p$ ? It would be odd to utter it in the explicit uncertainty context but it is perfectly fine in the explicit certainty contexts. We can capture this by saying that, when used to convey an inference, $p$ can only follow from (propositions taken to be) facts (consistent with a traditional knowledge-based norm for assertion). The only difference between must $p$ and $p$ in explicit certainty contexts might be that must $p$, by its modal meaning, makes explicit reference to a modal base and thus signals the reasoning process overtly.

Consider now a context where the speaker sees water pouring from the sky and concludes from this that it is raining. Traditionally, this context has been analyzed as a context of certainty. Yet plain $p$ is felicitous - It is raining! - but must $p$ is degraded - \# It must be raining! Why is that? We believe this is actually a context where reasoning is based on both a fact - that I see water pouring from the sky - and an assumption - that if I see water pouring from the sky that means that it is raining. However, this assumption about the significance of the fact is so highly conventionalized that it is taken as a fact. This view makes two predictions: First, must $p$ (unlike $p$ ) should be acceptable for people who are more aware of the assumption status and the fact that it may be wrong. This is confirmed by examples like von Fintel \& Gillies (2010)'s speaker who has been informed that there would be a movie shooting involving fake rain. Second, must $p$ (like $p$ ) should be acceptable for people who take the assumption as a fact but want to keep track explicitly of this added premise in their reasoning. This is confirmed by examples like von Fintel \& Gillies (2010)'s careful epistemologist. But so far we still predict only acceptability for must $p$. Why then is it degraded? We think that a third possibility is that, due to

3 Another possibility is that $g(w)$ is not empty but irrelevant - e.g., it might rank the worlds in $\bigcap f(w)$ w.r.t. whether $p$ and some other proposition $q$ is true or not in them. However, it is plausible to think that $f(w)$ and $g(w)$ are sensitive to the question under discussion, which should rule this case out.

4 Another way to capture this in terms of different accessibility relations (Portner 2009; Kaufmann, Condoravdi \& Harizanov 2006): Both epistemic must and the epistemic future can associate with

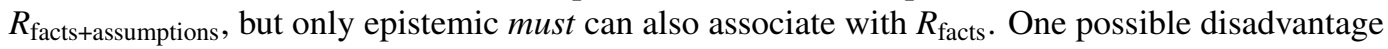
with this approach is that we now have two lexical entries for epistemic must. A separate but related issue will be pointed out in Fn. 8. 
its highly conventionalized status, the assumption is often conflated with the fact - if I see water pouring from the sky, then it is raining and if it is raining, then I see water pouring from the sky. Von Fintel \& Gillies (2010) propose must $p$ (unlike $p$ ) carries a requirement ${ }^{5}$ that must $p$ cannot be used if $p$ is already entailed by any single proposition in what they call the Direct evidence. We adopt this also, as follows: with must $p, p$ cannot be recognized as already part of $f(w)$, i.e., $p \notin f(w)$.

Finally, consider an utterance of $p$ vs. must $p$ in an out-of-the-blue context, such as (12). Given our explanation for the certainty case in $\S 2.2$, our predictions for out-of-the-blue contexts are now a bit more nuanced than on the plain Karttunen (1972) view articulated in $\S 2.1$. In particular, for these contexts we predict that must $p$ doesn't have to be understood as not entailing $p-$ it can also be understood as entailing $p$. This should depend on how the listener is willing to reconstruct the speaker's epistemic state - to a state as in our contexts of explicit uncertainty or to one as in our contexts of explicit certainty. We believe this prediction, which is a novel prediction with respect to the existing literature, is justified: if I ask Anna's secretary about her location and, after consulting her calendar, she tells me Anna must be in Honolulu now, this does not have to be taken as an indication of ignorance or uncertainty, it may also simply be taken as an explicit indication of reasoning. However, in many everyday situations a listener may still be biased towards inferring ignorance - so long as there are no relatively good reasons to infer certainty, it's always safer to infer uncertainty. Yet, even then, a listener can ask their interlocutor either 'Why are you uncertain?' but also 'How do you know that?', which shows that they don't necessarily rule out the possibility that the speaker has facts that entail $p$.

\subsubsection{Extension: must vs. the epistemic future in other contexts}

We saw that both must $p$ and [epistemic future] $p$ were fine in explicit uncertainty contexts. We captured this by saying that they are both compatible with conclusions based on facts+assumptions. But this predicts that in this type of contexts they should always be equivalent. Yet Ippolito \& Farkas (2018) show that in a context such as the one below, where the use of the modal can but doesn't have to be reconstructed to just facts, they are different - must $p$ sounds reasonable but [epistemic future] $p$ sounds completely speculative and therefore unreasonable in the context.

Maria has just given a very detailed description of her symptoms to her doctor. When she finishes, the doctor says:

It $\checkmark$ must / \# will / \# va / \# o be narcolepsy.

5 Given the cross-linguistic universality of this, von Fintel \& Gillies (2010) suggest this might be a quantity implicature. However, in the face of certain difficulties, they default to a presupposition analysis, but in light of further implicature effects as those mentioned in $\$ 2.3 .2$, we believe a implicature account might be more generally needed, or at least worth exploring. 
Epistemic modals, deduction, and factivity

Ippolito \& Farkas add to this an example with an explicitly clueless speaker as below, where must $p$ is out but [epistemic future] $p$ is perfectly fine.

(20) I don't have the slightest idea, he \# must / $\checkmark$ will / $\checkmark$ va / $\sqrt{ }$ o be home.

They conclude that epistemic must requires facts, but - contrary to its 'epistemic' label - the epistemic future does not: it can be based on no facts at all. (They in fact conclude that the epistemic future is never based on facts. See discussion in §2.4.)

Our account in its present form doesn't yet capture this, but we think there is a plausible way to extend it. Just like in Kratzer (2012)'s system epistemic modal reasoning is allowed in principle to be based just on facts - an empty ordering source - it is also in principle allowed to be based just on assumptions - an empty modal base. ${ }^{6}$ If the epistemic future allows an empty modal base and epistemic must does not, this captures their contrast in the clueless speaker context. Moreover, whenever, because of the use of the epistemic future, the context is reconstructed to an uncertainty context, if the fact that the premises consist not just of assumptions but also of facts is not made clear, then the context could in principle be reconstructed to either just assumptions or both facts and assumptions. This ambiguity predicts scalar implicature effects which, informally, might be described as follows: if the context had been one of both facts and assumptions, the speaker would have used must $p$, so the fact that s/he used [epistemic future] $p$ must mean that the reasoning was in fact based on just assumptions. This captures the speculative vibe of the epistemic future in the doctor context. This moreover makes predictions for a use of the epistemic future in out-of-the-blue contexts, where it can be reconstructed the same way, to either just assumptions or to facts and assumptions. In either case it is pitched against must, which can be reconstructed to either facts and assumptions or just facts. This captures sequences as below (from Fălăuș 2014, originally shown for Romanian), where the must $p$ continuation is read as denying that the reasoning is based on just assumptions or even on just facts and assumptions. The former is a cancellation of a scalar implicature that not must $p$ that effectively reconstructs must $p$ to facts and assumptions or just facts, and the latter a correction of the whole [epistemic future] $p$ assertion that effectively reconstructs must $p$ to just facts.

She will be home now. In fact, she must be home now.

\subsection{Previous literature}

There have been numerous separate accounts of epistemic must and the epistemic future in the literature but considerably fewer accounts that have looked at them together. We briefly review them below.

6 This would be a case where the set of worlds ordered by the ordering source are restricted by nothing other than, possibly, the question under discussion - see also Fn. 3. 
Winans (2016) starts from contrasts between must and English will in uncertainty contexts like The light is on. Typically, if the light is on, Anna is home. So, Anna must / \# will be home. She notes that the difference between this context and a context like our own It's 7 pm. Typically, if it's 7 pm, Anna is home. So, Anna must / will be home. is that here the guess can be understood as the reason for the evidence - the light is on because Anna is home - so the underlying reasoning schema is abductive. She proposes that will carries an anti-abductivity requirement, which is responsible for its restricted distribution. However, note that, by using time evidence in both our uncertainty and one of our certainty examples, we deliberately avoided an abductive reasoning schema - as Winans herself would say, the guess about Anna being home is not the cause for it being $7 \mathrm{pm}$, so the reasoning here is not abductive. And it is not clear at all that our other certainty examples are abductive either - e.g., 2 being even doesn't cause it to be divisible by 2 , rather, being divisible by 2 is what causes it to count as even. We conclude that our contrasts are not about anti-abductivity but about whether the facts entail $p$, as our minimal pair in (4)-(5) also shows.

Ippolito \& Farkas (2018) start from contrasts between must and the epistemic future like the ones we saw in the doctor and the clueless speaker example earlier. They take them to mean that the epistemic future is not in fact like epistemic must, and go on to articulate an account on which the epistemic future is in fact neither epistemic nor a necessity modal in the canonical sense -i.e., it is a universal quantifier over most likely propositions, where likelihood is assessed based on what is normally the case in the world of evaluation relative to a doxastic base. They argue this captures both why the epistemic future seems similar to epistemic must this comes from an inference from what is likely to what the speaker believes - and why it is incompatible with full knowledge and compatible with not having a clue this comes from the fact that it is not about knowledge. While this is a plausible way to look at the data, we believe an account of the sort we sketched is preferable - it not only offers a way to capture the contrasts but also to preserve existing insights that can derive the similarities (e.g., about the cross-linguistic temporal-aspectual similarity of the epistemic future to epistemic modals).

Finally, Giannakidou \& Mari (2018) focus on the similarities between epistemic must and the epistemic future in uncertainty contexts and analyze them as epistemic necessity modals. In order to derive the incompatibility of the epistemic future with certainty contexts, they argue that it presupposes that the modal base $-\bigcap f(w)-$ has to contain both $p$ and non- $p$ worlds. Note that this is essentially the same as our proposal for the uncertainty context - on our view when the context is such that $\bigcap f(w)$ doesn't entail $p$, and so it contains both $p$ - and non- $p$-worlds, $g(w)$ kicks in to pick out a subset that does. However, we also leave room for certainty - when the context is such that $\bigcap f(w)$ does by itself entail $p$, and so it contains only $p$-worlds, $g(w)$ plays no role, it is empty. Accordingly, we have a way to capture the contrast 
Epistemic modals, deduction, and factivity

between epistemic must and the epistemic future in certainty contexts, a contrast that the authors do not discuss.

\subsection{Summary}

We have argued that epistemic must and the epistemic future are both epistemic necessity modals whose quantificational domain is given by a modal base as restricted by an ordering source. A non-empty ordering source derives uncertainty, and an empty ordering source certainty. The epistemic future does not tolerate an empty ordering source, capturing our certainty puzzle.

\section{Proposal: the factivity puzzle}

Our second puzzle, the factivity puzzle, has to do with the fact that both epistemic must and the epistemic future can occur in the complement of a non-factive cognitive attitude predicate, but only epistemic must can also occur in the complement of a factive attitude predicate. We argue that the modal semantics we used to model (un)certainty and account for the certainty puzzle can help us capture the interaction of must and the epistemic future with the presupposition of a factive predicate also.

\subsection{Capturing the similarity under non-factive cognitive attitudes}

On a naive view of modal embedding under attitude predicates, the meaning of the modal is relative to worlds accessible from worlds first made accessible by the attitude predicate. For example, a sentence such as John believes it might be raining should have the meaning below.

(22) John believes it might be raining.

$$
\forall w^{\prime} \in \operatorname{BELIEVE}_{w, j} \exists w^{\prime \prime} \in \operatorname{Best}\left(\bigcap \mathbf{f}\left(\mathbf{w}^{\prime}\right), \mathbf{g}\left(\mathbf{w}^{\prime}\right)\right)\left[p\left(w^{\prime \prime}\right)\right]
$$

Hacquard (2010: 105) however remarks that this sentence doesn't seem to have this meaning, rather, it "seems to make the more modest claim that rain is compatible with what John believes." She proposes that "epistemic modality expresses possibilities/necessities given a particular information state, as determined directly by the embedding attitude, rather than a hardwired knowledge/doxastic state."7 Concretely, this would mean that (22) must in fact be analyzed as below.

7 This assumption is also used to make sense of other puzzles related to modal embedding under attitudes, e.g., Yalcin (2007)'s puzzle: Imagine that it's raining but \# it might not be. For more discussion of this, see Hacquard (2010), Anand \& Hacquard (2013) and references therein. 
(23) John believes it might be raining.

$\forall w^{\prime} \in \operatorname{BELIEVE}_{w, j} \exists w^{\prime \prime} \in \operatorname{BELIEVE~}_{\mathbf{w}, \mathbf{j}}\left[p\left(w^{\prime \prime}\right)\right]$

The first quantifier quantifies vacuously, so this simplifies to:

$\exists w^{\prime \prime} \in \operatorname{BELIEVE}_{w, j}\left[p\left(w^{\prime \prime}\right)\right]$

'There is a world compatible with what John believes in which it is raining.'

We propose that our example where epistemic must and the epistemic future appeared embedded in the complement of a cognitive attitude must be analyzed like this as well, as shown below.

(24) I think that Anna $\checkmark$ must $/ \sqrt{ }$ will $/ \checkmark$ va $/ \checkmark$ o be home now. $\forall w^{\prime} \in \mathrm{THINK}_{w, s p} \forall w^{\prime \prime} \in \mathrm{THINK}_{w, s p}\left[p\left(w^{\prime \prime}\right)\right]$

The first quantifier quantifies vacuously, so this simplifies to:

$\forall w^{\prime \prime} \in \mathrm{THINK}_{w, s p}\left[p\left(w^{\prime \prime}\right)\right]$

'All the worlds compatible with what the speaker thinks are worlds in which Anna is home.'

We argue that this extends to embedding of non-epistemic uses of must under a cognitive attitude. We illustrate below for a deontic use of must.

(25) I think that Anna must pay a fine.

$\forall w^{\prime} \in \mathrm{THINK}_{w, s p} \forall w^{\prime \prime} \in \mathrm{THINK}_{w, s p}\left[p\left(w^{\prime \prime}\right)\right]$

The first quantifier quantifies vacuously, so this simplifies to:

$\forall w^{\prime \prime} \in \mathrm{THINK}_{w, s p}\left[p\left(w^{\prime \prime}\right)\right]$

'All the worlds compatible with what the speaker thinks are worlds in which Anna pays a fine.'

The intuition behind this is as follows: even though, unembedded, 'Anna must pay a fine' is about rules, once embedded under the cognitive attitude predicate it is about knowledge/belief regarding the rules. More concretely, the speaker isn't using facts and laws to conclude deontically that must $p$, rather, s/he is using knowledge/beliefs about facts and laws to conclude epistemic-doxastically that must $p$. Thus, the underlying schema is not: Anna exceeded $40 \mathrm{mph}$. The law says that, if you exceed 40 mph, you pay a fine. Therefore, Anna must pay a fine. Rather, it is: I think that Anna exceeded $40 \mathrm{mph}$. I think that, if you exceed $40 \mathrm{mph}$, you pay a fine. Therefore, I think that Anna must pay a fine.

So the interpretation of epistemic/deontic/...must and of the epistemic future under a cognitive attitude is done relative to the worlds introduced by that attitude. We believe that for non-cognitive factives these are typically worlds compatible with a mixture of facts and assumptions, but they could also be worlds compatible with just facts or worlds compatible with just assumptions. A non-factive cognitive attitude such as think (but also other non-factive cognitive attitudes, e.g., believe, 
etc.) essentially acts like an out-of-the-blue unembedded context, and we expect the acceptability of must and of the epistemic future under think to be just in that case also. More concretely, if think is reconstructed to both facts and assumptions, both must and the epistemic future should be fine. As in unembedded contexts, this is the safest default reconstruction, which captures the default acceptability of both under think. However, if it is reconstructed to just facts, the epistemic future should be bad, and (cf. our discussion of epistemic must vs. the epistemic future in the clueless speaker contexts) if it is reconstructed to just assumptions, epistemic must should be bad. This is borne out: when placed in a context like our well-defined uncertainty and certainty contexts, which constrain exactly how think can be reconstructed, the patterns are as in the unembedded case, as the reader can verify.

\subsection{Capturing the contrast under factive cognitive attitudes}

Factive cognitive attitude predicates are traditionally taken to entail the same as their non-factive counterparts but to additionally presuppose the truth of their propositional complement at the evaluation world (see, e.g., Abrusán 2014 or Spector \& Egré 2015 for a recent endorsement of this view). For example, John knows that Anna is home entails that John believes/thinks that Anna is home, and presupposes that she is.

(26) John knows that Anna is home.

a. Truth conditions: $\forall w^{\prime} \in \mathrm{BELIEVE} / \mathrm{THINK}_{w, j}\left[p\left(w^{\prime}\right)\right]$

b. Presupposition: $p(w)$

But this only provides a solution for the case where the complement of a factive cognitive attitude is an unmodalized proposition. How does this transfer to our case of interest where the complement of the factive cognitive attitude is a modalized proposition? To our knowledge, the literature provides no answers.

We propose that, quite generally, a factive cognitive attitude predicate entails truth relative to an epistemic-doxastic modal base like that of think, but presupposes truth relative to a purely epistemic modal base. Concretely, we assume that, just like know, find out entails the same as believe or think, and that the truth conditions for the case with a must $p$ or a will/va/o $p$ complement are obtained as in (24). Furthermore, we argue that the factive presupposition is obtained by replacing the BELIEVE/THINK modal base from the truth conditions with a purely epistemic modal base - essentially, our $\bigcap f(w)$ from before, unrestricted by any $g(w)$.

I found out that Anna $\checkmark$ must / \# will / \# va / \# o be home now. $\quad(=(5))$

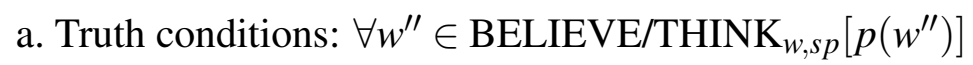

b. Presupposition: $\forall w^{\prime \prime} \in \bigcap f(w)_{w, s p}\left[p\left(w^{\prime \prime}\right)\right]$ 
Just as for think, we believe this works similarly for the embedding of other flavors of must - I found out that Anna must pay a fine plausibly fits with a reasoning schema of the form: I know/found out that if Anna exceeded $40 \mathrm{mph}$ on this road, then she pays a fine, and I know/found out that Anna exceeded 40 mphs on this road, so I know/found out that she must pay a fine.

So the interpretation of epistemic/deontic/...must and of the epistemic future under a factive cognitive attitude is, as for a non-factive cognitive attitude, relative to the worlds introduced by that attitude predicate. However, unlike a non-factive, a factive cognitive attitude also imposes a requirement that the context must be such that the facts entail $p$. That effectively means that a modal under a factive cognitive attitude is interpreted like a modal under a non-factive cognitive attitude presented in a certainty context, which, as discussed, is itself like a modal in an unembedded, certainty context. The contrast between epistemic must and the epistemic future then follows for the same reasons as in the latter context - the epistemic future does not allow a use where the facts already entail $p$, that is, a context where $g(w)$ is empty / where assumptions play no role. ${ }^{8}$

\subsection{Predictions}

\subsubsection{Prediction: know must p vs. know $p$}

Our account calls us to revisit know p - it has the same truth conditions as before, but a slightly different presupposition, and as such is now identical to know must p.

John knows that Anna is home.
a. Truth conditions: $\forall w^{\prime} \in \mathrm{BELIEVE} / \mathrm{THINK}_{w, j}\left[p\left(w^{\prime}\right)\right]$
b. Presupposition: $\forall w^{\prime} \in \bigcap f(w)_{w, j}\left[p\left(w^{\prime}\right)\right]$
$(\neq(26 b),=(27 b))$

Just as in unembedded contexts, we argue that the difference is that must $p$, and because of it know must $p$, requires $p \notin f(w)$.

\subsubsection{Prediction: know must p vs. know might p}

Our account also makes predictions with respect to epistemic possibility modals. Concretely, we predict that know might $p$ should presuppose that the epistemic state of the speaker is compatible with the truth of $p$.

8 Another way to capture this in terms of accessibility relations: Non-factive cognitive attitudes can associate with $R_{\text {assumptions/facts+assumptions/facts }}$ but factive cognitive attitudes can only associate with $R_{\text {facts. }}$. The embedded modal must match this relation (must quantify over the same worlds), yet only epistemic must can associate with $R_{\text {facts }}$ (as discussed in Fn. 4), capturing the contrast. An issue we see with this approach is that, by building the factive presupposition of the factive cognitive attitude directly into the accessibility relation, it yields a meaning that is too weak under negation. 
Epistemic modals, deduction, and factivity

(29) John found out that Anna might be home.

a. Truth conditions: $\exists w^{\prime \prime} \in \mathrm{THINK}_{w, j}\left[p\left(w^{\prime \prime}\right)\right]$

b. Presupposition: $\exists w^{\prime \prime} \in \bigcap f(w)_{w, j}\left[p\left(w^{\prime \prime}\right)\right]$

The presupposition of might $p$ thus generated seems to capture the correct meaning. Note also that it is much weaker, and so more easily satisfiable, than that of must $p$. This ties in nicely with cross-linguistic observations that existential epistemic modals embed more easily than universal epistemic modals (cf. Papafragou 2006, Rett 2012 for English; Anand \& Hacquard 2013 for Romance languages).

\subsection{Previous literature}

To our knowledge, there has been little descriptive discussion and no formal analysis of the epistemic future in the complement of (non-)factive cognitive attitudes. However, there have been attempts to look at the embedding of epistemic modals under attitudes in general. We touch on a few recent views below.

Papafragou (2006) discusses embedding of epistemic modals under emotive factives and argues that the acceptability of must depends on whether it can be interpreted objectively (felicitous) vs. subjectively (infelicitous). Rett (2012) however points out that might can also be either subjective or objective, yet that doesn't affect its felicity in these contexts, as it is always fine. She also shows that the contexts where epistemic must seemed to be fine only on what Papafragou called an 'objective' meaning were also cases where epistemic will was out. Our account can nicely capture these observations: on our view felicity depends on (a) objectivity - in the sense of entailment from facts; and (b) quantificational force - in the sense that for necessity modals the presupposition of a factive ends up being much stronger than for possibility modals, which, as we argued, might affect ease of embedding; but also (c) further differences between modals of the same force.

Anand \& Hacquard (2013) and Crnic (2014) discuss contrasts between epistemic possibility and necessity modals in the complement of various types of attitudes but not in the complement of cognitive factives. Since we are looking to derive differences within necessity modals and under factives, these accounts are not directly applicable. However, we pursue a similar approach - all these attitudes have some presupposition that goes through for some modals but not others, so our account belongs to the same general approach to epistemic modal embedding.

\subsection{Summary}

We have argued that the embedded use of epistemic must and the epistemic future under (non-)factive attitudes corresponds exactly to their unembedded use in 
Mihoc, Bhadra, and Fălăuş

(un)certainty/(non-)deduction contexts, and the same solution captures both.

\section{Conclusion and outlook}

Traditional intuitions that the epistemic future is fundamentally similar to epistemic must have been challenged by cross-linguistic data showing important empirical contrasts between the two. We discussed two such contrasts having to do with use in (un)certainty/(non-)deduction and (non-)factive cognitive contexts. We provided a solution on which the epistemic future and epistemic must are both epistemic necessity modals sensitive to a modal base and an ordering source, but differ in whether they allow an empty ordering source or not. We showed how, combined with a certain view of factive cognitive attitudes, this account captures both contrasts.

Our contrastive discussion of epistemic must vs. the epistemic future used mainly data in English and Romanian. To our knowledge, the certainty and the factivity puzzles are attested in other languages with an epistemic future, e.g., Italian or Spanish, but at this stage, the cross-linguistic extent of this behavior remains a matter of further empirical investigation.

The account we proposed also makes contributions beyond these starting puzzles. First, we contribute to debates on weak vs. strong epistemic must. We argue that epistemic must is in fact underspecified with respect to strength, as by default allowed by its semantics. This connects to, and improves on, recent work by Goodhue (2017).

Second, we contribute to debates on epistemic future vs. future tense. Since [epistemic future] $p$ cannot entail $p$, we encoded this as a lexical requirement on [epistemic future]. However, [future tense] $p$ can entail $p$, as shown by the fact that (i) it is perceived as a lie if $p$ is false at the designated future time (e.g., I will come to visit is a lie if I don't; cf. Comrie 1989: 53, cited in Salkie 2010); (ii) it is felicitous in our certainty and factive contexts, in contrast to [epistemic future] $p$. This suggests that, even on a unified analysis of epistemic future and future tense under a single epistemic modal meaning, we must still recognize two slightly different lexical variants, i.e., one that doesn't allow an empty ordering source and one that does. This connects to, though also challenges, (Giannakidou \& Mari 2018).

Third, we contribute to debates regarding the embedding of epistemic modals under attitudes. We have shown that differences can arise, and must be derived, not just between possibility and necessity modals but between various types of necessity modals also. This connects to, though potentially also challenges, recent approaches such as (Anand \& Hacquard 2013) and (Crnic 2014).

Overall, we hope to have shown that investigating the epistemic future alongside more canonical epistemic modals, in both embedded and unembedded contexts, is a fruitful way to breathe new life into old discussions, not only of epistemic modality but also of other related phenomena. 
Epistemic modals, deduction, and factivity

\section{References}

Abrusán, Márta. 2014. Weak island semantics, vol. 3. OUP Oxford.

Anand, Pranav \& Valentine Hacquard. 2013. Epistemics and attitudes. Semantics and Pragmatics 6(8). 1-59.

Comrie, Bernard. 1989. On identifying future tenses. In W. Abraham \& T. Janssen (eds.), Tempus - Aspekt - Modus: Die lexikalischen und grammatischen Formen in den Germanischen Sprachen, 51-63. Tübingen: Niemeyer.

Condoravdi, Cleo. 2003. Moods and modalities for will and would. Handout for invited communication at Amsterdam Colloquium.

Crnic, L. 2014. Pragmatics of epistemics in attitudes: A reply to Anand \& Hacquard (2013). Unpublished manuscript. https://semanticsarchive.net/Archive/ WNiZTVkM/crnic-modals.pdf.

von Fintel, Kai \& Anthony S Gillies. 2010. Must... stay... strong! Natural Language Semantics 18(4). 351-383.

Fălăus, Anamaria. 2014. Presumptive mood, factivity and epistemic indefinites in Romanian. Borealis-An International Journal of Hispanic Linguistics 3(2). $105-124$.

Fălăus, Anamaria \& Brenda Laca. 2014. Les formes de l'incertitude. le futur de conjecture en espagnol et le présomptif futur en roumain. Revue de Linguistique Romane 78. 313-366.

Giannakidou, Anastasia \& Alda Mari. 2016. Epistemic future and epistemic must: Nonveridicality, evidence, and partial knowledge. Mood, aspect, modality revisited: New answers to old questions 75-117.

Giannakidou, Anastasia \& Alda Mari. 2018. A unified analysis of the future as epistemic modality. Natural Language \& Linguistic Theory 36(1). 85-129.

Goodhue, Daniel. 2017. Must $\varphi$ is felicitous only if $\varphi$ is not known. Semantics and Pragmatics 10.

Hacquard, Valentine. 2010. On the event relativity of modal auxiliaries. Natural Language Semantics 18(1). 79-114.

Ippolito, Michela \& Donka F Farkas. 2018. Epistemic stance without epistemic modality: The Presumptive Future in Italian and Romanian .

Karttunen, Lauri. 1972. Possible and must. In John P. Kimball (ed.), Syntax and semantics, vol. 1, 1-20. Academic Press.

Kaufmann, Stefan, Cleo Condoravdi \& Valentina Harizanov. 2006. Formal approaches to modality. In William Frawley, Erin Eschenroeder, Sarah Mills \& Thao Nguyen (eds.), The expression of modality, 71-106. Berlin-New York: Mouton de Gruyter.

Kratzer, Angelika. 1981. The notional category of modality. In Hans-Jurgen Eikmeye \& Hannes Rieser (eds.), Words, worlds, and contexts, 38-74. 
Kratzer, Angelika. 1991. Modality. In Arnim von Stechow \& Dieter Wunderlich (eds.), Semantics: An international handbook of contemporary research, de Gruyter.

Kratzer, Angelika. 2012. Modals and conditionals: New and revised perspectives, vol. 36. Oxford University Press.

Mandelkern, Matthew. 2019. What 'must' adds. Linguistics and Philosophy 42(3). 225-266.

Mihoc, Teodora. 2012. The Romanian Presumptive Mood: Inferential evidentiality and upper-end degree epistemic modality: University of Ottawa MA thesis.

Mihoc, Teodora. 2014. The Romanian future-and-presumptive auxiliary. McGill Working Papers in Linguistics 24(1). 64-80.

Papafragou, Anna. 2006. Epistemic modality and truth conditions. Lingua 116(10). 1688-1702.

Portner, Paul. 2009. Modality. Oxford University Press.

Rett, Jessica. 2012. On modal subjectivity. UCLA Working Papers in Linguistics 16. $129-148$.

Salkie, R. 2010. Will: tense or modal or both? English Language and Linguistics 14(2). 187-215.

Spector, Benjamin \& Paul Egré. 2015. A uniform semantics for embedded interrogatives: An answer, not necessarily the answer. Synthese 192(6). 1729-1784.

Winans, Lauren D. 2016. Inferences of will: UCLA PhD dissertation. Yalcin, Seth. 2007. Epistemic modals. Mind 116(464). 983-1026.

Teodora Mihoc

Boylston Hall, 3rd floor

Harvard University

Cambridge, MA, 02138

tmihoc@fas.harvard.edu

Diti Bhadra

S313 Elliot Hall

University of Minnesota

Minneapolis, MN 55455

bhadra@umn.edu

Anamaria Fălăuş

CNRS, Laboratoire de Linguistique de Nantes

Chemin de la Censive du Tertre

44312 Nantes, France

anamaria.falaus@univ-nantes.fr 